\title{
Evaluation of Physicochemical, Functional and Sensory Properties of Carob Pulp Beverage (Ceratonia Siliqua L)
}

\author{
Mouad Achchoub ${ }^{1,2 *}$, Hanane Azzouzi ${ }^{1,2}$, Loubna Elhajji ${ }^{2}$, \\ Mohammed Benbati ${ }^{1}$, Kaoutar Elfazazi ${ }^{1 *}$ and Souad Salmaoui ${ }^{2}$ \\ ${ }^{1}$ Agro-food Technology and Quality Laboratory, Regional Center of Agricultural Research of Tadla, \\ National Institute of Agricultural Research (INRA), Avenue Ennasr, BP 415 Rabat Principale, \\ 10090 Rabat, Morocco. \\ ${ }^{2}$ Laboratory of environmental engineering, faculty of science and technology, \\ Sultan Moulay Slimane University, Béni Mellal, Morocco. 23000.
}

http://dx.doi.org/10.13005/bbra/2945

(Received: 22 September 2021; accepted: 26 October 2021)

In Morocco, carob tree (Ceratonia siliqua L.) is of considerable socio-economic importance, helping to improve the income of rural populations and to develop the economy of mountain areas. However, the primary use of the carob's pulp is generally limited in Morocco to animal feed. As a result, the current research suggests a novel pulp-based product designed for human consumption. The main purpose of this work is to characterize a new formulated carob beverage and assess its physicochemical, biochemical, and sensory quality. Two formulas of carob beverages were prepared with two different sugar concentrations (formula A:5 g/100 $\mathrm{mL}$ sugar; formula $\mathrm{B}: \mathbf{1 0} \mathrm{g} / \mathbf{1 0 0} \mathrm{mL}$ sugar). Measurements of $\mathrm{pH}$, titrable acidity, and colour were performed to assess the physicochemical parameters. Total polyphenols and tannins contents were determined as important functional and biochemical parameters. Regarding sensory analysis, preference test, triangle test, hedonic test, and descriptive test, were evaluated. The colour of the two formulations was dark red orange, as determined by chromameter method. For formulae $A$ and $B$, the titrable acidity was $(1.450 \pm 0.025) \mathrm{g}$ Citric Acid Equivalent (CAE) $/ \mathrm{L}$ and $(1.450 \pm 0.031) \mathrm{CAE} g / \mathrm{L}$, respectively, and the Brix was $(11.67 \pm 0.22){ }^{\circ} \mathrm{Bx}$ and $(15.33 \pm 0.22)$ ${ }^{\circ} \mathrm{Bx}$, respectively. The polyphenols content was $(98.8 \pm 0.0019) \mathrm{mg}$ Gallic Acid Equivalent (GAE) $/ 100 \mathrm{~mL}$ for formula $A$ and $(97.7000 \pm 0.0017) \mathrm{mg} \mathrm{GAE} / 100 \mathrm{~mL}$ for formula $B$. The tannin level was $(24.500 \pm 0.027) \mathrm{mg}$ Catechin $(\mathrm{CE}) / 100 \mathrm{~mL}$ and $(25.400 \pm 0.017) \mathrm{mg} \mathrm{CE} / 100 \mathrm{~mL}$ for the formula $A$ and formula $B$ samples, respectively. The sensory analysis tests revealed a distinct difference between the two formulae. In fact, the formula B was highly preferred compared to formula $\mathrm{A}$, also the most prominent features in the drink were colour, smell, flavour, and sweetness.

Keywords: Biochemical; Beverage; Carob pulp; Polyphenols; Sensory Analysis.

Ceratonia siliqua $L$ is the scientific name for the carob tree. It is one of the most useful trees in the Mediterranean basin and other Mediterranean-like areas, due to its economic and environmental implications. This plant has been successfully introduced into places with limited agronomic resources due to its remarkable agroecological characteristics, such as drought and salt resistance, adaptability to poor soils, and minimum cultural requirements. It is derived 
from the Greek word keras (horn) and the Latin word siliqua (pod), alluding to the hardness and form of the pod. Ceratonia siliqua L. belongs to the family Leguminosae, order Rosales, and is a Caesalpiniaceae of the genus Ceratonia. ${ }^{1,2}$ The total area of world carob production is estimated to be 14421 hectares in 2018 and 14366 hectares in 2019, Morocco and Israel are the countries with the most cultivated land. Carob production in the world is expected to reach 45540 tonnes in 2018 and 46600 tonnes in 2019. Morocco is the top producer, followed by Israel, Turkey, Algeria, Tunisia, Lebanon, and finally Ukraine. ${ }^{3}$ The pulp of the carob pod makes for around $90 \%$ of the fruit's mass, it is high in sugar (48-72\%), including saccharose, fructose, and glucose, which gives it a natural sweetness. However, it is poor in protein $(2 \%-6 \%)$ and fats $(0.5 \%-0.7 \%) .57 \%$ of the total amino acids in the pulp are aspartic acid, glutamic acid, alanine, leucine, and valine. It also contains a considerable quantity of polyphenols $(16 \%$ $-20 \%$ mainly tannins) and has a high fibre content (4.2 to $9.6 \%$ ). It also includes $18 \%$ cellulose and hemicellulose, as well as a substantial amount of minerals $(\mathrm{K}, \mathrm{Ca}, \mathrm{Na}, \mathrm{Fe}$, and $\mathrm{Mg})$, vitamins, and ash (1.5\%-2.4\%). ${ }^{4,5}$ Variety, habitat, growing techniques, origin, and, in certain cases, harvest season all impact the chemical composition of pod pulp. ${ }^{4,6,7,8}$

Due to these characteristics, carob has been utilized as a feed and food source for over 4000 years, particularly during times of food scarcity, owing to its sugary pulp as a cheap source for animal nutrition and for humans in times of famine..$^{9,10,11}$ Even though carob pods contain tannins, which have the potential to function as antinutritional factors by reducing the digestion of proteins in pig diets as reported by MariscalLandin ${ }^{12}$.in the other hand The seed and leaves contain the most anti-nutrients, such as trypsin inhibitor and phytic acid, and hence the pulp has the highest nutritional value of all carob tree products ${ }^{13}$.

Carob kibbles have long been used to make a famous Turkish boiling juice. ${ }^{14,15}$ To our knowledge, the standardization of traditional carob products is hardly known. This is due to the absence of recorded research on long-term, nonindustrial food processing methods and limited manufacturing.

The goal of this project is to develop new beverage recipes that will improve the value of carob pulp, a by-product of carob processing. The aim of this study was to characterize and analyse the physicochemical, biochemical, and the sensory quality of various carob beverage formulas using pulp from carob samples collected in Beni Mellal-Khenifra region, in order to translate consumer preferences into tangible and welldefined properties and rely on them to make carob beverages a valuable food resource.

\section{MATERIAL AND METHODS}

\section{Vegetal material}

The vegetal material consists of mature carob pods. The latter was collected between June and September 2018, from the region of Beni Mellal Khenifra, specifically Afourar which is characterized by an altitude of $636 \mathrm{~m}$.

Formulation and preparation of the carob drink

The carob drink was made in several stages, the first of which was crushing, which consisted of reducing the size and changing the shape of the carob fruit in order to facilitate the sorting of the pulp seed. This process was done by hand with a cleaver, then there's the separation, which involves separating the seeds from the cut pulp, The pulp will be used to make beverages, after that comes the cleaning, we submerged the crushed pulp in lukewarm water baths 2-3 times, making sure that any stuck substances were removed with our hands. We dried the washed pulp in an oven (Memmert UM 500) at $80^{\circ} \mathrm{C}$ for 18 hours. Then we dried it for 2 to 3 days in the greenhouse. The pulp was milled into powder using an industrial grinder (Retsch, rotor beater mill SR 300), which allowed us to achieve the desired particle granulometry of less than $0.5 \mathrm{~mm}$. Then comes the diffusion phase. 750 grams of carob pulp powder and 4 litres of water were combined in a stainless-steel cooking pot. We used a laboratory hotplate to diffuse it over high heat until it reached $80^{\circ} \mathrm{C}$, then kept it at that temperature for $60 \mathrm{~min}$ while constantly stirring it with a kitchen whisk. The aqueous extract was then separated from the solid phase using a nylon $1 \mathrm{~mm}$ filter (Puritec 1mm Nylon Mesh Filter). We developed two formulae. The first (formula A) dissolves $5 \mathrm{~g}$ of sugar per $100 \mathrm{~mL}$ of beverage, whereas the second (formula B) dissolves $10 \mathrm{~g}$ of sugar per $100 \mathrm{~mL}$ of beverage. We filled $250 \mathrm{~mL}$ 
glass bottles that had been cleaned, dried, and sterilized previously. After cold conditioning in the bottles, pasteurization was achieved by a vertical floor-standing laboratory autoclave without drying (Raypa AES-75). The bottles were cooled with a cold-water spray after being heated to $110^{\circ} \mathrm{C}$ on a pre-set scale for 10 minutes. The pasteurized bottles were kept cold at $4{ }^{\circ} \mathrm{C}$ after pasteurization.

Physicochemical and biochemical characterisation of the carob beverage Chemical Reagents

Catechin, ethanol, Folin-Ciocalteu reagent, gallic acid, hydrochloric acid, sodium carbonate, sodium hydroxide, and vanillin were purchased from Mastoral diffusion (Mohammedia Morocco).

\section{Physicochemical characteristic} pH

A calibrated $\mathrm{pH}$ meter (Hanna HI98161 Professional Foodcare Portable $\mathrm{pH}$ Meter) was used to determine the beverage's $\mathrm{pH}$ according to the (AOAC 981.12, 1990) ${ }^{16}$. At room temperature, the $\mathrm{pH}$ meter electrode (FC2023 Foodcare $\mathrm{pH}$ electrode) was dipped into a beaker holding 10 $\mathrm{mL}$ of sample. The procedure was carried out three times.

\section{Titrable acidity}

The titrable acidity was determined by titrating $10 \mathrm{~mL}$ of the drink with $0.1 \mathrm{~N}$ sodium hydroxide solution until a $\mathrm{pH}$ of 8.1 was achieved. The procedure was repeated three times. The titratable acidity of a beverage is measured in grams of citric acid per $100 \mathrm{~mL}$ of liquid ${ }^{17}$.

Brix

A refractometer (Portable Refractometer, VBR50) was used to determine the proportion of soluble dry matter, or Brix (expressed in ${ }^{\circ} \mathrm{Bx}$ ) according to AOAC method 932.14 ${ }^{18}$.

Colour

The Chromameter (Konica Minolta CR415 Sensing Inc., Osaka (Japan)) which gives the Colorimetric variables L", a" and b". Colorimetric variables $\left(L^{*}, a^{*}, b^{*}\right)$ were measured and chroma $\left(\mathrm{C}^{*}\right)$ and hue $\left(\mathrm{H}^{*}\right)$ were calculated from:

$$
\begin{aligned}
& \left.C^{*}=\sqrt{\left(a^{* 2}\right.}+b^{* 2}\right) \\
& H^{*}=\tan ^{-1}\left(\frac{a}{b}\right)
\end{aligned}
$$

For each beverage preparation, three measurements were taken, and the average value was reported. Color measurement was performed on $30 \mathrm{~mL}$ samples in Petri dishes against a background of white tiles ${ }^{19}$.

\section{Biochemical characteristic}

\section{Determination of Polyphenols}

Singleton and Rossi ${ }^{20}$ described the FolinCiocalteu reagent for determining total polyphenols, slightly modified as follows: Pour $200 \mu \mathrm{L}$ of diluted beverage $(1 / 100)$ into test tubes, followed by 1.5 $\mathrm{mL}$ of diluted Folin-Ciocalteu reagent (1/10). 1.2 $\mathrm{mL}$ of saturated sodium carbonate $(75 \mathrm{~g} / \mathrm{L})$ is added into the solution. After shaking, the mixture is incubated at room temperature for 90 minutes. The blank is prepared in the same manner without the beverage. The optical density of the generated combination at $760 \mathrm{~nm}$ is measured using a UV-Visible spectrophotometer (Schimadzu-UV2401PC).

\section{Determination of condensed tannins}

The determination of tannins was carried out by the vanillin method described by JulkunenTitto $^{21}$. In test tubes, $250 \mu \mathrm{L}$ of pure beverage was added, followed by $500 \mu \mathrm{L}$ of ethanol. After that, $1.5 \mathrm{~mL}$ of $4 \%$ vanillin was added. Following that, $0.5 \mathrm{~mL}$ of $37 \% \mathrm{HCl}$ solution was added. The solution was well mixed. After 15 minutes of incubation at room temperature, the absorbance was measured at $500 \mathrm{~nm}$ using a UV-Visible spectrophotometer (Schimadzu-UV-2401PC). The blank test was prepared in the same manner as the sample, but without the inclusion of the extract.

\section{Sensory analysis}

A tasting panel of 35 tasters (18 men, 17 women), their ages range from 19 to 51 , completed preference, hedonic, triangle, and profile tests; following the steps outlined by Meilgaard ${ }^{22}$; Before being subjected to the different analyses, the tasters were given basic training. The two samples that were tasted were one with $5 \mathrm{~g}$ of sugar per $100 \mathrm{~mL}$ of drink and the other with $10 \mathrm{~g}$ of sugar per 100 $\mathrm{mL}$ of drink. Tasters can pick which of two samples they prefer in the preference test. The hedonic test allows the taster to assess a product's level of appreciation. The triangle questionnaire requires the taster if he or she can distinguish between the two items' overall sensory quality, while the profile test allows tasters to evaluate the strength of the characters given by the presenter. Panel members were given samples in a $50 \mathrm{~mL}$ glass container with a number code. A palette cleanser was provided in 
the form of a cracker (without salt) and lukewarm water. On an 8-point scale, the panellists were asked to report the sensory score and relative relevance of each sensory characteristic for each formulation.

\section{Statistical analysis}

The data was statistically evaluated using the IMB SPSS Statistics V21 program. All the tests were done in triplicate, and the findings are given as (average SD). A statistical study of variance (ANOVA) according to (X2 Test) was used to perform these various tests, with the statistical significance threshold set at $\mathrm{P} 0.05$.

For sensory analysis A two-tailed binomial test is used to analyse the preference test findings. The total number of judges who favour each sample is added together, and the significance of the totals is determined using the statistical table. The descriptive categories were transformed to numerical ratings once both samples were examined. The Hedonic test data were collated and analysed using Analysis of Variance (ANOVA). We gave the right response with a $(+)$ when they had properly identified the separate sample or with a (-) when they had incorrectly identified the separate sample after assessing the two samples. The triangle test results were provided in tabular form. The total number of tasters with accurate responses (X) was compared to the total number of tasters (n) using the statistical table, and the significance level was calculated. The descriptive categories of the strength of the provided attributes were transformed into numerical ratings after the sample was evaluated. The profile test findings were provided in the form of a radar chart.

\section{RESULTS AND DISCUSSION}

\section{Physicochemical and biochemical parameters}

The physicochemical and biochemical properties of carob-based pulp beverage are represented in table 1 :

According to Table 1, the formula A and (B) samples have a $\mathrm{pH}$ of $(5.170 \pm 0.054$, $5.060 \pm 0.010)$, respectively. These results are similar to those reported by Elfazazi ${ }^{8}$ on traditional carob drink from Béni Mellal region. Regarding the titratable acidity, formula (A) and (B) samples have

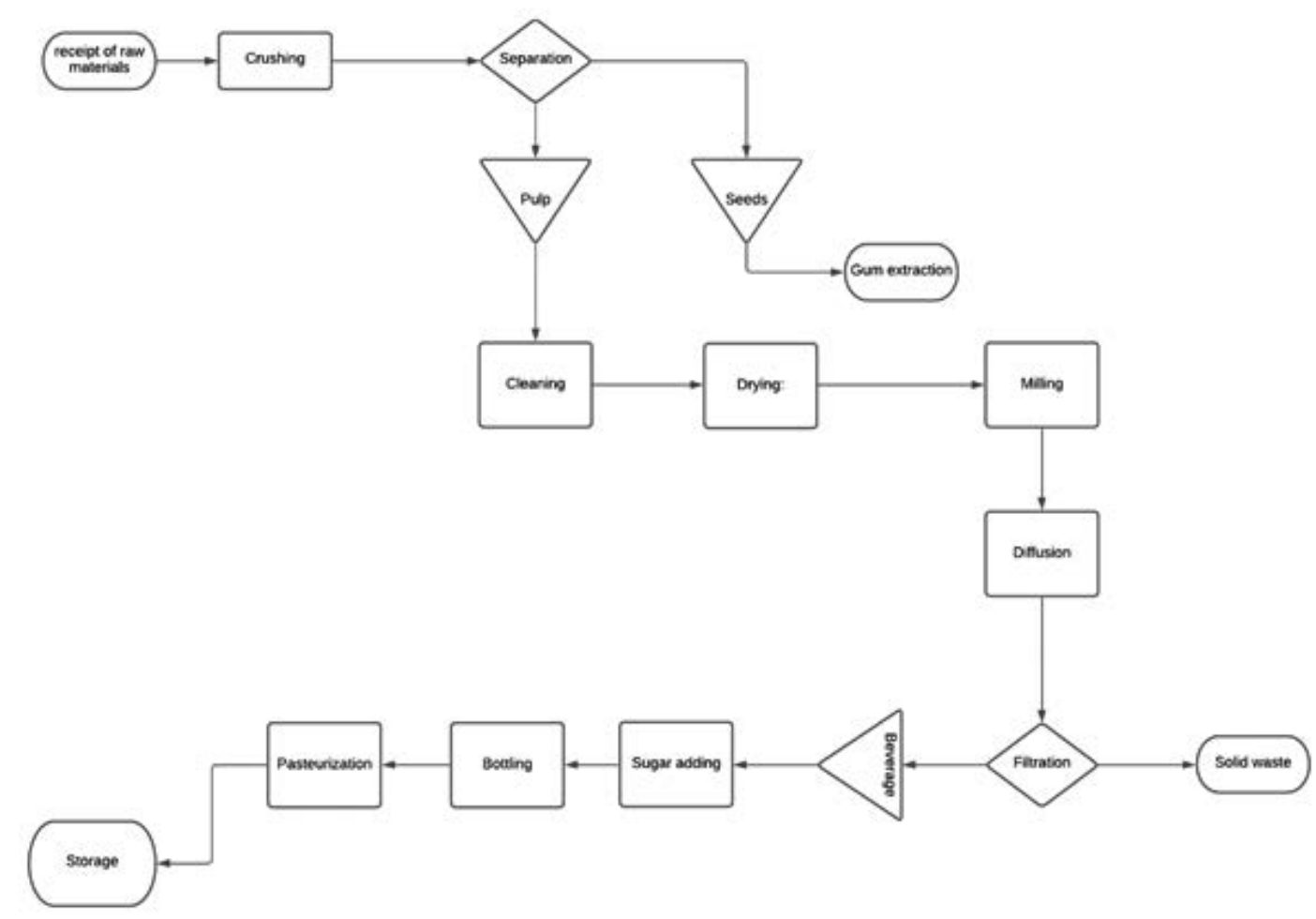

Fig. 1. Process for making carob pulp beverage 
an acidity of $(1.450 \pm 0.025 \mathrm{CAE} \mathrm{g} / \mathrm{L} ; 1.420 \pm 0.031$ $\mathrm{CAE} \mathrm{g} / \mathrm{L}$ ), respectively. This beverage is classified as slightly acidic based on its $\mathrm{pH}$ and titratable acidity. The titratable acidity values of pomegranate juice and orange juice $\left(2.72 \pm 0.03 \mathrm{CAE} \mathrm{g/1}{ }^{23}, 7.68\right.$

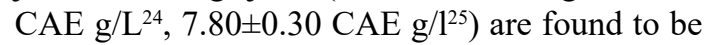
higher our carob-based drink Due to its high citric acid content.

The Brix of formula B $(15.33 \pm 0.22)$ ${ }^{\circ} \mathrm{Bx}$ is significantly higher than that of formula $\mathrm{A}$ $(11.67 \pm 0.22)^{\circ} \mathrm{Bx}$, which is due to the added sugar difference.

For color's parameters $\left(L^{*}, a^{*}, b^{*}\right)$, the formula A values were $(30.46 \pm 2.19 ; 42.89 \pm 1.05$; $42.75 \pm 4.21)$, respectively. The colour of the carob beverage in formula $\mathrm{A}$, which is dark red orange, may be calculated using these variables. In fact, $54.9 \%$ of the colour is red, $11.76 \%$ green, and $0 \%$ blue. The beverage color has a hue of 44.9 and $\mathrm{C}$ of 60.56 , a saturation of $100 \%$, and a lightness of $27 \%$ in the colour space.

Regarding formula $\mathrm{B}$, theses parameters were $(40.81 \pm 4.32,48.82 \pm 3.29$, and $63.99 \pm 9.3)$, respectively. This formula is also dark red orange. It contains $70.2 \%$ red, $19.61 \%$ green, and $0 \%$ blue. It has a hue of 52.7 and $C$ of 80.49 , a saturation of $100 \%$, and a brightness of $35 \%$ in the colour space.

These findings show that, even though the two formulae appear to be the same colour, there are minor differences in the drink's colour, such as the red and green constitutions and the degree of change produced by the different sugar concentrations in each recipe. The carob beverage's colour is similar to that of coffee, although coffee is deeper, with $26.27 \%$ red, $17.25 \%$ green, and $15.69 \%$ blue.

For the biochemical parameters (table1), the total polyphenol content (TPC) of formula (A) and formula (B) were $(98.8000 \pm 0.0019 \mathrm{mg}$ $\mathrm{GAE} / 100 \mathrm{~mL})$ and $(97.9000 \pm 0.0017 \mathrm{mg} \mathrm{GAE} / 100$ $\mathrm{mL}$ ), respectively which confirm that our beverage is a rich source of total polyphenols. In fact, the obtained results show that our carob beverage's TPC are higher to other fruit juices: apple (33.9 $\pm 0.4) \mathrm{mg} \mathrm{GAE} / 100 \mathrm{~mL}$, orange $(45.5 \pm 0.2) \mathrm{mg}$ $\mathrm{GAE} / 100 \mathrm{~mL}$, pineapple (35.8 \pm 0.3$) \mathrm{mg} \mathrm{GAE} / 100$ $\mathrm{mL}$, grape $(51.9 \pm 0.1) \mathrm{mg} \mathrm{GAE} / 100 \mathrm{~mL}^{26}$, and prickly pear pulp $(21.8 \pm 0.3) \mathrm{mg}$ GAE/100 mL ${ }^{27}$ in other research paper we found that green tea $(85 \pm 3) \mathrm{mg} \mathrm{GAE} / 100 \mathrm{~mL}$ black tea $(72 \pm 15)$ $\mathrm{mg} \mathrm{GAE} / 100 \mathrm{~mL}$ drinking chocolate $(60 \pm 7) \mathrm{mg}$ $\mathrm{GAE} / 100 \mathrm{~mL}$ ground coffee $(53 \pm 7) \mathrm{mg} \mathrm{GAE} / 100$ $\mathrm{mL}$, red tea $(38 \pm 3) \mathrm{mg} \mathrm{GAE} / 100 \mathrm{~mL}$ hot cocoa $(30 \pm 7) \mathrm{mg} \mathrm{GAE} / 100 \mathrm{~mL}^{28}$.

For the condensed tannin contents of the two samples, the formula (A) and formula (B) values are $(24.500 \pm 0.027) \mathrm{mg} \mathrm{CE} / 100 \mathrm{~mL}$ and ( $25.400 \pm 0.017) \mathrm{mg} \mathrm{CE} / 100 \mathrm{~mL}$, respectively.

When compared to pomegranate juice (12.70 \pm 0.06$) \mathrm{mg} \mathrm{CE} / 100 \mathrm{~mL}^{29}$, the two formulas of carob beverage had a greater concentration of condensed tannins. This is similar to what was

Table 1. Physicochemical and biochemical parameters of carob beverage (Formula A \& B)

\begin{tabular}{|c|c|c|c|}
\hline \multicolumn{2}{|c|}{$\begin{array}{l}\text { Physico chemical } \\
\text { Parameters }\end{array}$} & $\begin{array}{l}\text { Carob beverage } \\
\text { Formula A }\end{array}$ & $\begin{array}{l}\text { Carob beverage } \\
\text { Formula B }\end{array}$ \\
\hline \multicolumn{2}{|c|}{$\mathrm{Ph}$} & $5.170 \pm 0.054$ & $5.060 \pm 0.010$ \\
\hline \multicolumn{2}{|c|}{ Titrable acidity(CAE g/L) } & $1.420 \pm 0.031$ & $1.450 \pm 0.025$ \\
\hline \multicolumn{2}{|c|}{${ }^{\circ}$ Brix } & $11.67 \pm 0.22$ & $15.33 \pm 0.22$ \\
\hline & $\mathrm{L}^{*}$ & & $30.46 \pm 2.19$ \\
\hline \multicolumn{4}{|c|}{$40.81 \pm 4.32$} \\
\hline & $a^{*}$ & $42.89 \pm 1.05$ & $48.82 \pm 3.29$ \\
\hline \multirow[t]{2}{*}{ Colour } & $b^{*}$ & $42.75 \pm 4.21$ & $63.99 \pm 9.30$ \\
\hline & $\mathrm{C}$ & & 60.56 \\
\hline \multicolumn{4}{|l|}{80.49} \\
\hline \multirow{3}{*}{\multicolumn{2}{|c|}{$\begin{array}{l}\text { Hue } \\
\text { Total Polyphenol Content (TPC) } \\
\text { Condensed tannin content (CTC) }\end{array}$}} & 44.9 & 52.7 \\
\hline & & $97.9000 \pm 0.0017$ & $98.8000 \pm 0.0019$ \\
\hline & & $24,500 \pm 0.027$ & $25,400 \pm 0.017$ \\
\hline
\end{tabular}


found by Elfazazi ${ }^{8}$ with a concentration of $(20.7 \pm$ 0.4) $\mathrm{mg} \mathrm{CE} / 100 \mathrm{~mL},(28.1 \pm 0.3) \mathrm{mg} \mathrm{CE} / 100 \mathrm{~mL}$ in two Moroccan region Ait Oum Lbakht and Dir El Ksiba carob pods drink, respectively.

\section{Sensory analysis}

\section{Consumer-oriented tests}

\section{Preference test}

The results are analysed using a two-tailed binomial test. $68.57 \%$ preferred the formula B sample. According to the two-tailed binomial test table, the probability for $\mathrm{X}=24$ and $\mathrm{n}=35$ is 0.041 . Therefore, results were statistically significant, and it was concluded that the tasting panel generally preferred the drink (B) with $10 \mathrm{~g} / 100 \mathrm{~mL}$ sugar content more than the drink (A) with $5 \mathrm{~g} / 100 \mathrm{~mL}$ sugar content.

\section{Hedonic test}

For the parameters of colour, aroma, astringency and overall appearance, the F coefficients calculated for the treatment do not exceed the F coefficient in the table of 4.17, it was concluded that there is no significant difference between the means of the hedonic results for the two formulas A and B. The F coefficient calculated for the tasters exceeds the F coefficient of 1.84 in the table. Thus, there was a significant effect on the tasters. These results show that the tasters did not have the same assessments, and the tasters' preference ratings for each criterion were not similar.

For the sweetness criterion we find that the F coefficients calculated for the treatment and for the tasters do not exceed the F coefficients in the table, so there was no significant effect attributable to the treatments and to the tasters. It is concluded that the tasters had a non-significant preference for all samples, as the number of panels was not sufficient, and therefore the number of panels needs to be increased to have significant results.

\section{Product-oriented tests Triangular test}

The statistical table ${ }^{30}$ indicates that for a set of 35 tasters and 20 correct answers, the significance level is 0.003 . From these results it was concluded that the difference between the samples was significant at the 0.003 probability level, since pd" 0.05 and 20 of the 35 tasters had correctly chosen the different sample. The formula B drink, which had a sugar content of $10 \mathrm{~g} / 100 \mathrm{~mL}$, was therefore quite different from the formula $\mathrm{A}$ drink $(5 \mathrm{~g} / 100 \mathrm{~mL})$.

\section{Profile test}

Based on the results of the preference, hedonic, and triangle tests, we were able to determine the formula chosen by the panel (Formula B), therefore we opted to conduct the

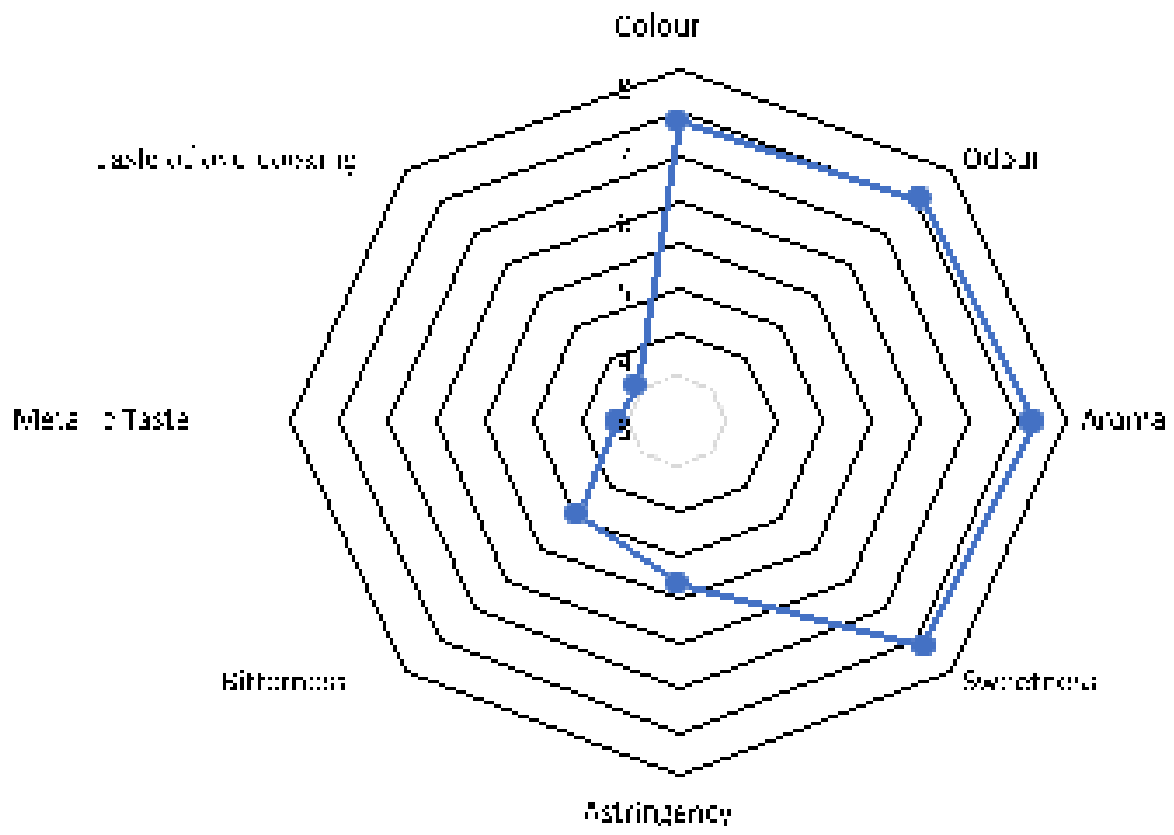

Fig. 2. Medians of the scores of the sensory and appreciation parameters attributed to the carob beverage 
profile test on this formula to define its sensory characteristics.

The results of formula B profile test are shown in Figure 2:

Results in Figure 2 indicate that almost all tasters have similar intensity of rating choices for each criterion.

The parameters of colour, smell, aroma, and sweetness of the beverage are perceived as more intense. While the parameters of baked taste and metallic taste were found to be less intense, which shows the absence of metallic taste and baked taste to that of the experimental drink. Also, bitterness and astringency were rated by a low intensity.

\section{CONCLUSION}

The production of two pulp-based carob drink formulae through the samples collected at the level of Béni Mellal-Khénifra was established in order to provide the best recipe to satisfy market demands for a new dietetic beverage. The physicochemical, functional and sensory quality of the two formulas were evaluated to assess the characteristics of the carob beverage processed and the degree of its acceptability regarding Moroccan consumer.

Despite the fact that both formulas have the same colour, there are minor differences in their red and green compositions, as well as the degree to which the amount of sugar fluctuates, all of which contribute to the beverage's colour. The $\mathrm{pH}$ drops when sugar levels rise, and the difference in sugar content between these two samples has an impact on the titratable acidity. In terms of secondary metabolites, the carob beverage contains $98.8 \mathrm{mg} /$ $100 \mathrm{~mL}$ and $97.9 \mathrm{mg} / 100 \mathrm{~mL}$ total polyphenols for formula $\mathrm{A}$ and formula $\mathrm{B}$, respectively. Condensed tannins were found to be $24.5 \mathrm{mg} / 100 \mathrm{~mL}$ in formula A and $25.4 \mathrm{mg} / 100 \mathrm{~mL}$ in formula B. Both formulae are also high in total polyphenols, which offer tannins a unique nutritional character, compared with other fruit juice products. The preference test, which was conducted for the sensory evaluation, indicated that the $10 \mathrm{~g}$ sugar formula is the most preferred formula. The triangle test revealed a difference between the two formulae. The hedonic test indicated a discrepancy in customer perceptions of the drink's qualities.
Finally, the descriptive test revealed the degree to which the various characteristics were present.

This assessment of the physicochemical and biochemical characterizations of carob grown in the Beni Mellal region would allow the best cultivar features to be proposed for the creation of new technological transformation products with the highest agro-industrial profitability. Consumer sensory testing revealed that the carob beverage tested is satisfactory. As a result, the Moroccan carob tree, which is currently underutilized in the country's food sector, might be a promising food, nutritional, and dietetic product.

\section{ACKNOWLEDGEMENT}

The authors would like to thank the staff of the Regional Centre of Agricultural Research of Tadla, National Institute of Agricultural Research (INRA) for the support and cooperation during this study.

\section{Conflict of Interest}

The authors declare no conflict of interest.

\section{Funding Source}

This study was totally supported by the research funds of INRA Morocco.

\section{REFERENCES}

1. Sbay H. Le Caroubier au Maroc : un arbre d'avenir. Centre de recherche forestière, 2008.

2. Albanell T. E. Caracterización morfológica, composición química y valor nutritivo de distintas variedades de garrofa (Ceratonia siliqua L.) cultivadas en España. Doctoral thesis. Universitat Autònoma de Barcelona. 2010.

3. Fao. Data from the Faostat statistical data base. 2019. Www.Fao.Org

4. Batlle I.Carob tree: Ceratonia siliqua L.-Promoting the conservation and use of underutilized and neglected crops. Biodivers. Int. J. 1997; 17; Vol. 17.

5. Avallone R., Plessi M., Baraldi M., \& Monzani, A. Determination of chemical composition of carob (Ceratonia siliqua): protein, fat, carbohydrates, and tannins. Journal of food composition and analysis, 1997; 10(2): 166-172..

6. Bengoechea C., Romero A., Villanueva A., Moreno G., Alaiz M., Millán, F., \& Puppo M. C. "Composition and structure of carob (Ceratonia siliqua L.) germ proteins." Food chemistry, 2008; 107(2): 675-683.

7. Elfazazi K., Jbilou M., Assaidi A., Benbati M., 
\& Harrak H. "Morphological and biochemical variability of Moroccan carob (Ceratonia siliqua L.) produced in Beni Mellal region." Int. J. Pure App. Biosci, 2017; 5(4): 14-21.

8. Elfazazi K., Harrak H., Achchoub M., \& Benbati M. "Physicochemical criteria, bioactive compounds and sensory quality of Moroccan traditional carob drink." Materials Today: Proceedings, 2020; 27: 3249-3253.

9. Mohammed B., Abdelhafid K., Abdelmajid H., Wiam B., Kaoutar E., \& Hanane A. "Effect of Carob Pulp (Ceratonia Siliqua L.) on Fattening Performance, Carcass Characteristics and Meat Quality of Moroccan Breed Deroua Lambs." Biosciences Biotechnology Research Asia, 2021; 18(2): 297.

10. Bernardo-Gil M. G., Roque R., Roseiro L. B., Duarte L. C., Gírio F., \& Esteves P.. "Supercritical extraction of carob kibbles (Ceratonia siliqua L.)." The Journal of Supercritical Fluids, 2011; 59: 36-42.

11. Karababa E., and Yalçýn Copkuner. "Physical properties of carob bean (Ceratonia siliqua L.): An industrial gum yielding crop." Industrial crops and Products, 2013; 42: 440-446.

12. Mariscal-Landín G., Avellaneda J. H., de Souza T. R., Aguilera A., Borbolla, G. A., \& Mar, B. Effect of tannins in sorghum on amino acid ileal digestibility and on trypsin (EC 2.4. 21.4) and chymotrypsin (EC 2.4. 21.1) activity of growing pigs. Animal Feed Science and Technology, 2004; 117(3-4), 245-264.

13. Mahtout R., Ortiz-Martínez V. M., SalarGarcía M. J., Gracia I., Hernández-Fernández F. J., Pérez de los Ríos A., ... \& LozanoBlanco L. J. Algerian carob tree products: A comprehensive valorization Analysis and future prospects. Sustainability, 2018; 10(1): 90.

14. Yousif A.K., and Alghzawi H.M. "Processing and characterization of carob powder." Food chemistry, 2000; 69(3): 283-287.

15. Ercan Y., Turhan I., and Karhan M. “Optimization of ethanol production from carob pod extract using immobilized Saccharomyces cerevisiae cells in a stirred tank bioreactor." Bioresource technology, 2013; 135: 365-371.

16. Horwitz William., P. Chichilo., and Helen R. "Official methods of analysis of the Association of Official Analytical Chemists." Official methods of analysis of the Association of Official Analytical Chemists. (1970).

17. BOLAND, F. E. Acidity (titratable) of fruit products. Official methods of analysis of $A O A C$ international, 1995; 2: 10.

18. AOAC, 2006. Official Method 932.14. Solids in Syrups. Official Methods of Analysis of AOAC
International, 18th Ed. AOAC International, Gaithersburg, MD, USA.

19. Yawadio R., Morita N., Color enhancing effect of carboxylic acids on anthocyanins. Food Chemistry, 2007; 105: 421-427.

20. Singleton V.L., and J.A.Rossi. "Colorimetry of total phenolics with phosphomolybdicphosphotungstic acid reagents." American journal of Enology and Viticulture, 1965; 16(3): 144-158.

21. Riitta J.T. "Phenolic constituents in the leaves of northern willows: methods for the analysis of certain phenolics." Journal of agricultural and food chemistry, 1985; 33(2): 213-217.

22. Meilgaard M., Civille G.V., and B. T. Carr. "Measuring responses." Sensory evaluation techniques, 1999; 3: 43-57.

23. Vegara S., Martí N., Lorente J., Coll L., Streitenberger S., Valero M., \& Saura D. "Chemical guide parameters for Punica granatum cv.'Mollar'fruit juices processed at industrial scale." Food chemistry, 2014; 147: 203-208.

24. Azzouzi, H., Elfazazi, K., Achchoub, M., Chafki, L., Jbilou, M., \& Salmaoui, S. Effect of thermal pasteurization on the physicochemical stability and nutritional quality of moroccan valencia late orange juice. Int. J. Eng. Sci. 2018;277-283

25. Esteve M.J., Frigola A., Rodrigo C. Effect of storage period under variable conditions on the chemical and physical composition and colour of Spanish refrigerated orange juices. Food And Chemical Toxicology, 2005;43: 1413- 1422.

26. Balasundram N., Kalyana S., and Samir S. "Phenolic compounds in plants and agriindustrial by-products: Antioxidant activity, occurrence, and potential uses." Food chemistry, 2006; 99(1): 191-203.

27. Fernández-López J. A., Almela L., Obón J. M., \& Castellar R."Determination of antioxidant constituents in cactus pear fruits." Plant Foods for Human Nutrition, 2010; 65(3): 253-259.

28. Zujko M E., and Anna M.W. “Antioxidant potential and polyphenol content of beverages, chocolates, nuts, and seeds." International Journal of Food Properties, 2014; 17(1): 86-92.

29. Muhacir-Güzel N., Türkyýlmaz M., Yemip O., Taðý P., \& Özkan M. "Changes in hydrolysable and condensed tannins of pomegranate (Punica granatum L., cv. Hicaznar) juices from sacs and whole fruits during production and their relation with antioxidant activity." LWT-Food Science and Technology, 2014; 59(2): 933-940

30. Watts, B., Ylimaki, G., Jeffery, L., \& Elias, L. (). Basic sensory methods for food evaluation Ottawa. The International Development Research Centre.1989; pp 59-68. 